\title{
Narrativas errantes de uma noite de verão quando D. Educação saiu para comprar cigarro...
}

\author{
Jorge Eiró
}

\section{$\mathrm{ntermezzo}$}

$\Gamma$ rata-se de um artigo no campo educacional arquitetada com Larte: um Artigo. Dessa forma, uma escrita artista que prevê, sobretudo, a disposição para o ensaio, a experimentação, a criação... E que, com esse desejo, inspire uma experiência de escritura que se aventure a criar linhas de escrita que explorem as relações de multiplicidade entre o ver, o ler e o escrever: ESCREVERLER. Onde as formas se mostrem indizíveis e as palavras invisíveis.

Parte-se de uma expedição-experiência-pesquisa que investe sobre o território da arte, explorando os processos de criação artística, especialmente, em torno dos desenhos de uma trupe de artistas-professores. Nesse território estamos no reino da criação, operando a invenção com uma "vontade de pesquisa" que rasga o espaço, escuta estrelas e afina os sentidos com o pensamento de Deleuze, para quem pensar significa, sobretudo, criar!

Uma pesquisa-educacional-com-arte como acontecimento pode se fazer em diferentes variações, intensidades, modulações e velocidades, assumindo de forma criativa as mais inusitadas e surpreendentes nomenclaturas, tais como "Pesquisa Transcendental, Experimental, Vital, Caótica, Artística, Esquizopesquisa, e outros 
tantos nomes a serem inventados, sonhados, delirados, inspirada pelo pensamento deleuzeano da diferença" (Corazza, Tadeu e Zordan, 2004, p. 9). Decorre desse raciocínio que esta pesquisa conduza os superjectos do campo da educação a explorar o território da arte, dele extraindo e operando em suas "múltiplas linguagens - tais como pintura, música, literatura, ciência, cinema, poesia, imagens, figuras, emoções, gestos, corpos, que, embora heterogêneos, se afectam uns aos outros" (ibid, p. 10).

\section{Prefiro não escrever...}

Como estamos tratando de uma experiência de escrita-artista, falemos, inicialmente, das agruras da escritura...

É lugar-comum no meio acadêmico aquele momento delicado, mais ou menos aos 20 minutos do segundo tempo da concepção da dissertação ou da tese, quando ocorre um enguiço na maquinaria da escrita. As palavras empedram, a fala não flui e o texto trava. Que nem futebolzinho de retranca: caímos naquele joguinho sem graça de meio-campo embolado, apenas trocando passes de lado a lado, distantes do gol, usando táticas teórico-metodológicas de defesa, sem conseguir sair daquele zero a zero apático e sem efetuar qualquer jogada que levante a galera. Desse jeito, na fase de qualificação, levamos vaia da torcida e os cartolas da banca são impiedosos, demitindo o time inteiro. Despencamos, então, num vácuo e sentimos um fastio de linguagem. Uma calmaria nos abate nas águas da pesquisa, a modorra do texto nos causa náuseas e chegamos até o ponto de rejeitá-lo, sem conseguir retomá-lo a contento. $\mathrm{O}$ devir da escrita padece e não consegue pegar no tranco, muito menos ganhar potência. 
Comparo essa situação crítica de travamento da escrita à "Síndrome de Bartebly". Trata-se de Bartebly, um escrivão, conhecido personagem concebido pelo escritor Herman Melville, que, aos poucos, sucumbe a uma atitude contemplativa, permanecendo dia após dia em sua mesa de trabalho sem conseguir fazer absolutamente nada. Enrique Vila-Matas, um dos expoentes da literatura espanhola contemporânea, retoma a essência do personagem de Melville em "Bartleby e companhia" e, a partir dela, diagnostica o que considera uma espécie de "síndrome", um estado de entorpecimento que acomete a todos aqueles que renunciam a qualquer atividade criativa, ou que dela se veem desprovidos. Numa série de narrativas, ele então elenca uma galeria de escritores que

[...] mesmo tendo consciência literária muito exigente (ou talvez precisamente por isso), nunca chegam a escrever; ou então escrevem um ou dois livros e depois renunciam à escrita; ou, ainda, após retomarem sem problemas uma obra em andamento, fiquem, um dia, literalmente paralisados para sempre. (Vila-Matas, 2004).

Portanto, é se divertindo à custa da própria angústia criativa que este pesquisador narratesista relata os momentos dramáticos dos impasses na escrita de sua tese. Os espíritos da escrita, intercessores que geralmente me assediam durante a madrugada me sussurrando palavras-chave, repentinamente ficaram mudos e se recusavam a fazer download para que eu baixasse a psicografia tesista. Não pintava nem um zombeteiro das letras. Não conseguia sentir nem um arrepio de escrita! Nem um toque, nem uma faísca de criatividade. Na-di-ca-de-na-da! O dia raiava e o caderno de artista, meu diário de bordo que fica sempre de plantão bem ao lado da minha rede-canoa-da-preguiça, permanecia em branco. 
E eu insone... Imerso numa deprê profunda, não havia defumação de "desenrola-língua", nem banho de "abre-caminho-das-palavras", nem passe de médium-escrevinhador que fizessem destravar a escritura àquela altura do doutoranato. Sentia-me acometido por uma variação tropical da tal síndrome de apatia criativa, uma espécie de "dengue de Bartebly".

Foi então que, no auge da crise, doente-de-não-escrever e agravado por um estado delirante de febre, resolvi, em desespero, meter a cara no temporal que desabava sobre a Mangueirosa naquela noite turbulenta, com o intuito de, ao menos, aplacar a quentura dos meus infernos. Foi quando, ao sair à rua, um relâmpago me chicoteou as ventas e o estrondo do trovão me estremeceu a carcaça, o que fez com que, de repente, me desatinasse a escrever logo em seguida. Sob o efeito do transe provocado pelo curto-circuito, desaguou essa narrativa contando...

\section{Era uma vez uma tese..}

Como já mencionado, este pedaço de tese, de uma narratese, é um artigo de Arte. Uma investida experimental de escrita-artista que leva os intercessores da criação para atuar na seara da Educação. E, em torno dela e por amor a esta bela dona, para a formulação afetuosa de uma educriação artista!... Eu diria, uma cartografia de afectos que, vezenquando, saudavelmente, acontecem de contagiar D. Educação. Esta senhora, que não consegue esconder as peias da vida por trás de sua beleza de ar antigo, converte-se em um personagem conceitual a la Deleuze nesta aventura de escrita. Ela, em um momento de crise, reúne-se a outros personagens igualmente conceituais, parceiros seus (trapaceiros, vejam lá!) articulistas, jogadores, desenhistas e, em conjunto, tramam esta escritura a devir... 
Numa noite chuvosa Dona Educação encontra-se com Senhora Filosofia, Madame Arte, Lady Literatura e Mister Arquitetura (sem dispensar o auxílio estratégico de Rainha Ciência) para traçar um mapa, provisório que seja, impreciso, mas delicado, das muitas narrateses que constituem sua imanência,... uma vida, para subsidiar e inspirar sua pesquisa e suas linhas de escritura. Sob as bênçãos de Deleuze e Guattari, Barthes e Borges, Almodóvar e Tarantino, Beatles e Bod Dylan, Chico, Gil e Caetano, e em meio a bares boêmios, cafés filosóficos, saraus musicais, grêmios literários, liceus e companhias artísticas tantas outras, riscam, rabiscam, rasgam as coordenadas dessa cartografia, colorem o mapa, pintam o sete. A trama reside em uma experiência no fora dos regimentos e protocolos institucionais das academias, tudo para ver D. Educação mais leve, acesa em sua multiplicidade imanente. Para apreciar, finalmente, sua perseguida tese aflorar. Que tesão Dona Flor, Dona Educação! Deixa a menina sambar, deixa a menina criar...

\section{Narrativas errantes de uma noite de verão em}

\section{que D. Educação saiu para comprar cigarro...}

Noite tempestuosa... Chapa quente, carne trêmula à flor da pele... D. Educação, encontrava-se assombrada por seus demônios teóricos, conceituais, metodológicos, epistemológicos na formulação de sua tese. A escrita não fluía, parecia travada, ressentia-se de leveza, de uma abordagem que se mostrasse mais sedutora, de, ao menos, uma cantada mais lírica, um capítulo poético. Faltavalhe emoção, o sentido inédito das teses: a maçã despencando na cabeça e anunciando a gravidade, o cintilar das luzes da eureka, a lira inspiradora da liga do álcool, o arrepio na nuca, a campainha 
do clitóris tocando, a sirene do recreio... Às vezes, todo aquele esforço intelectual the parecia apenas mais um daqueles enfadonhos trabalhos acadêmicos que a professorinha levava todo dia pra casa, mas que não lhe dava prazer e só provocava o adoecimento docente. Doente numa folia, sentia que sua tese precisava lhe proporcionar... tesão! Mas, enfim, indagava-se, que tese? "O que será que será que me queima por dentro?... Preciso esfriar a cabeça”. Estressada, resolveu sair no meio daquele baita temporal, sem guarda-chuva, sem lenço, nem documento. "Na chuva?... É pra se molhar...". E tentar aplacar os infernos que ardiam em suas entranhas e não concediam o desejo da escrita. "Se alguém perguntar por mim, diz que eu fui por aí...", gravou a canção na caixa de mensagem, "só vou voltar quando eu me encontrar!”. E, então, aquela senhora que nunca havia fumado resolveu sair para comprar cigarro...

Ao passar numa encruzilhada, avistou a Senhora Filosofia, velha amiga de guerra, que a convidou para se abrigar debaixo da marquise do boteco da esquina. Um boteco daqueles sórdidos e sem nome sequer, ou se tinha algum era um nome bem trash, algo tipo Suely e Ventania, os proprietários da biboca.

- Ô, Dona Educação, que é que há? A senhora, tão conceituada, sempre cheia dos protocolos curriculares, me aparece aí, toda molhadinha...

- Por isso mesmo, tô de saco cheio! Resolvi dar uma saída em busca de ar puro, senão sufoco...

- Quer um cigarro? -, perguntou Filosofia.

- Não, você sabe que eu não fumo. Mas... Quer saber? Acenda um aí pra mim, vai...

- Vamos entrar? Estou com alguns velhos amigos nossos lá dentro. 
Numa mesa bem lá nos fundos daquele enfumaçado bas-fond, sentados e conversando em meio a uma instalação de garrafas de diferentes cores, estilos e teores etílicos, encontravam-se Madame Arte, Mister Arquitetura e Lady Literatura. Gargalhavam sabe-se lá de quê, talvez pelo fato do tal Mister estar a boliná-las, sempre com a intenção de tirar uma casquinha de suas estéticas e línguas. Arte é uma fêmea luxuriosa, bela e criativa, toda metida à rica. Na verdade, uma pobre remediada, doidivana e devassa. Conta-se que, vez em quando, La Belle de Jour, se prostitui. Mister Arquitetura, indeciso em ser engenheiro ou decorador (agora inventaram a palavra designer, mais chique, mas fresco!), vive dividido entre a geometria e a plástica, entre a matemática e a estética. É uma espécie de "Seu Flor e suas Duas Mulheres" que se desdobra para atender às maisons de sua digníssima esposa Rainha Ciência e de sua amada amante Madame Arte. Lady Literatura é uma fofoqueira que não perde a oportunidade de lançar mão de todos os argumentos de qualquer campo de conhecimento para formular uma ficção que muitas vezes se sobrepõe a verdade dos fatos. "Ora, a vida é uma ficção!", diz, defendendo-se, blasé que só ela. A todo-poderosa Rainha Ciência não a tolera, mas a respeita, pois frequentemente também se apropria da sua escrita poética para ilustrar suas teorias, teoremas, postulados. A verdade é que as duas não conseguem esconder uma atração mútua, uma certa dependência. Ou, como costuma alfinetar D. Educação, que as duas curtem uma transa interdisciplinar, como também notam os amigos comuns, interlocutores, no afã de amenizar as disputas entre vaidades intelectuais. Os pós-modernos apostam num certo lesbianismo entre as duas. Questões de língua... E de linguagem. 
- Olá, D. Educação, quanto prazer! A senhora por aqui, metida neste inferninho numa alta madrugada? -, pergunta em uníssono o ménage-a-trois.

- É que hoje eu estou num daqueles dias, a fim de experimentar novas coisas. Pedagogias profanas, estéticas da existência, quem sabe?... Hoje estou mais pra lá do que pra cá, estou pra "La Mala Educación"! -, e deu uma risada atípica a sua conduta habitual.

- A Senhora vai beber o quê?

- Todas!

- Hummm... Sugiro aquele coquetel-vontade-de-potência, recomendou Filosofia: doses bem servidas de gin Deleuze e champanhe Barthes adicionadas a uma cerveja alemã Nietzsche 100 anos, tudo on the rocks, um drinque especial que faz a diferença, Educação. Às lolitas de plantão, o professor-barman Hubert recomenda acrescentar uma dose de vodka Nabokov, afrodisíaco, so exciting!

- Mora na Filosofia! Indicado como pós-tudo, restaura até as energias utópicas e não dá ressaca, garanto! -, completou Arte.

- Então, um brinde ao bar-academia, um drinque a esta escola dos infernos. Viva Dionísio! Viva la vida! -, exclamou entusiasmada a Educação.

Ao estalar dos copos, procurando aliviar as tensões da amiga, Arte convida Educação a escreviver e pintar o sete, no seu estilo:

- Relaxa, Educa! Veja só: viver como eu, viver com Arte, não é senão uma questão de estilo, uma forma criativa de viver essa vida besta. Escreve isso aí, Literatura. Pensa nisso, ô Filosofia. Cola comigo que é só sucesso! -, finalizou gargalhando, debochada. 
Mister Arquitetura, só de bubuia, ali, sorrindo. Seus olhos cintilavam, admirando a conversa e projetando um cenário espetacular para abrigar aquela encenação da vida. Naquele momento, todos já bastante relaxados, inicia-se então aquele papo-cabeça-de-boteco, cada um puxando a brasa pro seu peixe-frito...

- Borges, meu pupilo, já previa a ideia de internet em seu Aleph, 70 anos atrás”, comenta Literatura.

- Eppa! A arquitetura hipertextual das redes digitais que conectam o mundo virtual corresponde ao conceito de rizoma do meu orientando Deleuze -, rebate Filosofia.

- Tsss..., tudo está relacionado a uma ideia de espaço arquitetônico, minhas lindas. O Labirinto Mitológico, a Torre de Babel, a Biblioteca de Alexandria, por exemplo, meninas. Arquiteturas destinadas a conectar e confundir os homens. O que o teu Borges usou em suas arquiliteraturas.

Papo vai, papo vem, cada qual contando suas narrativas de vida, altas biografias entrecruzadas, os quatro cavaleiros do pós-calypso e mais a guerreira Educação resolveram então brincar de mapear suas histórias, simulando um jogo, um lance de dados. Inspirado nos Jogos Aleatórios da Teoria do Caos, presenteado por Lady Ciência, Mister Arquitetura propõe uma espécie de "banco cartográfico rizomático". O procedimento metodológico dessa jogatina consiste em que os jogadores, vendados, apontem o dedo para um lugar qualquer no mapa e, em ritornelos de punctum em punctum, de lá extraiam as informações desejadas. No final da noite, todos já pra lá do Marco da Légua, festejaram, dançando como Zaratustra. Os outros notívagos ainda presentes no bar não entenderam nada... 
Dia clareando, céu cintilante de Van Gogh, a Sr. ${ }^{a}$ Educação volta pra casa sentindo-se a própria Sr. ${ }^{a}$ Liberdade, uma Dona Flor e seus infinitos maridos e amantes, se danando a cantar pela rua "abre as asas sobre nós...”. De alma lavada, elabora um extrato, uma espécie de cartografia daquele estranho e criativo jogo da vida realizado ao longo da madrugada insone. Os dados estavam lançados e a tese havia, finalmente, aflorado: Alea jacta est...

\section{Referências}

AQUINO, Julio Groppa; CORAZZA, Sandra Mara (org.). Abecedário: Educação da diferença. Campinas: Papirus, 2009.

BARTHES, Roland. Aula. Tradução e posfácio de Leyla Perrone-Moisés. São Paulo: Cultrix, 1979.

BARTHES, Roland. O Rumor da Lingua. São Paulo: Martins Fontes, 2004.

CORAZZA, Sandra Mara. Artistagens: Filosofia da diferença e educação. Belo Horizonte: Autêntica, 2006.

CORAZZA, Sandra Mara. Introdução ao Método Biografemático. Porto Alegre, 2009. Artigo, 20p. (Texto dig. PDF).

CORAZZA, Sandra; TADEU, Tomaz; ZORDAN, Paola. Linhas de Escrita. Belo Horizonte: Autêntica, 2004.

DELEUZE, Gilles. A Ilha Deserta. São Paulo: Iluminuras, 2012.

DELEUZE, Gilles. A Imanência: uma vida. Porto Alegre: Educação e Realidade, 2002.

DELEUZE, Gilles. Conversações. São Paulo: Ed. 34, 2000.

DELEUZE, Gilles; GUATTARI, Félix. O que é a filosofia? Trad. Bento Prado Jr. e Alberto Alonso Muñoz. Rio de Janeiro: Ed. 34, 2005.

DELEUZE, Gilles; PARNET, Clair. Diálogos. São Paulo: Escuta, 1998. 
GONÇALVES, Jadson. Biografemática e Formação: Fragmentos de Escrita de uma Vida. Belém, Pará: PPGEDU/ICED/UFPA. Tese de Doutorado, abril 2013, 127 p. (Texto em pdf).

PASSOS, Eduardo; KASTRUP, Virgínia; ESCÓSSIA, Liliana da (org.). Pistas do Método da Cartografia: Pesquisa, intervenção e produção de subjetividade. Porto Alegre: Sulina, 2009.

PERRONE-MOISÉS, Leyla. Texto, Crítica, Escritura. São Paulo: Martins Fontes, 2005.

ROLNIK, Suely. Cartografia Sentimental: transformações contemporâneas do desejo. Porto Alegre: Sulina, 2006.

VILA-MATAS, Enrique. Bartebly e Companhia. São Paulo: Cosac Naif, 2010.

Jorge Eiró nasceu em Belém do Pará. É Artista Plástico e Arquiteto, formado pela UFPA. Doutor em Educação pela UFPA e professor do curso de Arquitetura dessa universidade. Realizou cinco exposições individuais: Jorge Eiró (1987), “Solo" (1990), “Idade Mídia” (1994), "Exegese” (1996) e “Cartografias” (2002). Participou de exposições coletivas nacionais e internacionais. Obteve premiações no Salão Arte Pará e no Salão de Arte Contemporânea do Maranhão. Membro dos Conselhos Curadores da Galeria de Arte da UNAMA e do Museu de Arte do Centro Cultural Brasil-Estados Unidos, tendo executado diversas ações curatoriais em exposições realizadas em Belém do Pará. 